\title{
Reflexões sobre a crítica pós-colonial e a questão da mestiçagem no romance Estação das chuvas, de José Eduardo Agualusa
}

José Luís Giovanoni Fornos ${ }^{1}$

\begin{abstract}
This essay brings concepts and themes of the so-called postcolonial criticism, based on its main scholars. Rainy Season, a novel by the writer José Eduardo Agualusa, is analyzed considering the theme of miscegenation. To do so, it resumes a chapter of the book in which two characters discuss the role of literature and negritude in the context of Angolan resistance to Portuguese colonialism. The conclusions of the debate refer to the favorable positions of the characters by Agualusa around miscegenation as a significant element of social democracy.
\end{abstract}

Keywords: Postcolonial criticism; Hybridism; Angolan Novel.

Resumo: O presente ensaio apresenta conceitos e temas da chamada crítica pós-colonial, recorrendo aos seus principais estudiosos. Igualmente analisa Estação das chuvas, romance do escritor José Eduardo Agualusa, considerando o tema da miscigenação. Para tanto, retoma um capítulo do livro em que duas personagens discutem o papel da literatura e da negritude no contexto de resistência angolana ao colonialismo português. As conclusões do debate referendam os posicionamentos favoráveis das personagens de Agualusa em torno da mestiçagem como elemento significativo da democracia social.

Palavras-chave: Crítica pós-colonial; Hibridismo; Romance Angolano

Introdução

O presente ensaio apresenta, num primeiro momento, aspectos da crítica pós-colonial, discutindo seus limites e acréscimos no âmbito das identidades híbridas culturais. Num segundo, traz a análise de um dos capítulos do romance Estação das chuvas (1996), em que o escritor angolano José Eduardo Agualusa discute questões relacionadas à contribuição e o papel da categoria da mestiçagem no âmbito social e literário.

A crítica pós-colonial, iniciada por aqueles autores qualificados como intelectuais da diáspora negra ou migratória - fundamentalmente imigrantes oriundos de países pobres que vivem na Europa Ocidental e na América do Norte - teve, na crítica literária, sobretudo na Inglaterra e nos EUA, a partir dos anos 1980, suas áreas pioneiras de difusão. Em primeiro lugar, a crítica pós-colonial não constitui propriamente numa única matriz teórica. Segundo Sérgio Costa,

1 Doutor em Letras pela PUCRS e professor da Universidade Federal do Rio Grande (FURG). 
Trata-se de uma variedade de contribuições com orientações distintas, mas que apresentam como característica comum esforço de esboçar, pelo método da desconstrução dos essencialismos, uma referência epistemológica crítica às concepções dominantes da modernidade (COSTA, 2006, p. 84).

Em segundo lugar, a episteme pós-colonial testemunha "as forças desiguais e irregulares de representação cultural", intervindo "nos discursos ideológicos da modernidade que tentam dar uma normalidade hegemônica ao desenvolvimento das histórias diferenciadas de nações, raças, comunidades, povos" (BHABHA, 1998, p. 239). Homi Bhabha defende a ideia de cultura como transnacional e tradutória. A cultura como estratégia de sobrevivência, escreve Bhabha, é tanto "transnacional como tradutória" (BHABHA, 1998, p. 248). Para o autor, "a cultura é tradutória porque as histórias espaciais de deslocamento tornam a questão de como a cultura significa, ou o que é significado por cultura" (BHABHA, 1998, p. 248). A defesa do transnacional como categoria de investigação ocorre porque os discursos contemporâneos "estão enraizados em histórias específicas de deslocamento cultural” (BHABHA, 1998, p. 241). A mobilidade de indivíduos e comunidades configura novas territorialidades, perturbando a mecânica cultural e histórica dos pertencimentos. $^{2}$

É desta maneira que "o estudo da literatura mundial poderia ser o estudo do modo pela qual as culturas se reconhecem através das projeções de alteridade" (BHABHA, 1998, p. 33). Em consequência, o terreno da literatura mundial poderia ser "as histórias transnacionais de migrantes, colonizados ou refugiados políticos. $\mathrm{O}$ centro de tal estudo não seria nem a soberania de culturas nacionais nem o universalismo da cultura humana" (BHABHA, 1998, p. 33).

Bhabha, ao reavaliar os conceitos de culturas nacionais homogêneas, ao problematizar a transmissão consensual de tradições históricas ou comunidades étnicas orgânicas, põe em questão a própria base do nacionalismo, promovendo um profundo processo de redefinição de tais estudos. Nessa readequação, outras vozes - as chamadas minorias - constituir-se-iam em tema internacional, desde que tais sujeitos fossem compreendidos à luz do hibridismo cultural. Tais sujeitos se situariam nas "margens deslizantes do deslocamento cultural", recusando os traços étnicos e raciais "inscritos na lápide fixa da tradição" (BHABHA, 1998, p. 20). Essas diferenças ocorrem no processo mesmo de sua manifestação, elas não são uma entidade ou expressão de um estoque cultural acumulado, não havendo um vínculo pré-determinado a um lugar na estrutura social.

Também Edward Said (1999) traz a ideia de empréstimos culturais, próprios de qualquer sociedade em sua formação. De acordo com o estudioso, a "história de todas as culturas é a história dos empréstimos culturais” (SAID, 1999, p. 275), observando que as culturas não são impenetráveis. A cultura nunca é uma questão de propriedade, de emprestar e tomar emprestado com credores absolutos, mas de "apropriações, experiências comuns e interdependências de todo o tipo entre culturas diferentes. Trata-se de uma norma universal" (SAID, 1999, p. 275). Em outra passagem, Said escreve: "devido ao imperialismo, todas as culturas estão mutuamente imbricadas, nenhuma é pura

2 São importantes as reflexões e reivindicações teóricas de Paul Gilroy ao defender a tese de um Atlântico negro como unidade de análise única e complexa do mundo moderno para produzir uma perspectiva transnacional e intercultural, em oposição às abordagens nacionalistas ou etnicamente absolutas. A história do Atlântico negro "propicia um meio para reexaminar os problemas de nacionalidade, posicionamento, identidade e memória histórica" (GILROY, 2008, p. 59). 
e única, todas são híbridas, heterogêneas, extremamente diferenciadas, sem qualquer monolitismo" (SAID, 1999, p. 28).

Com a presença dos sujeitos pós-coloniais, efeito da expansão global, fruto do processo de colonização e das lutas de independência nacionais, bem como das guerras étnico-civis em países do chamado Terceiro Mundo, há uma revisão do estatuto epistêmico das ciências e das diferentes tradições teóricas, recebendo as mesmas novos impulsos em seus estudos. ${ }^{3}$ A crítica pós-colonial dá testemunho de tal investida ao indagar acerca das diferenças culturais e dos processos de hibridação como fator epistêmico na compreensão das nações e comunidades.

Eduardo Coutinho (2003) enfatiza o significado desses locais de cultura - dentre os quais a América Latina - , em contrapartida ao modelo eurocêntrico até então tido como referência. Para o autor, o desafio levantado por críticos como Edward Said, Homi Bhabha e Gayatri Spivak ao processo sistemático instituído pelas nações colonizadoras de inventariar outras culturas alcança enorme repercussão, ocasionando, em lugares como a Índia, a África e a América Latina, reivindicações de constituição de uma História calcada na tradição local, cujo resgate se tornara indispensável.

Neste caso, pergunta-se: estariam os objetos do pós-colonial associados a determinados contextos históricos e geográficos? É correto circunscrever a crítica pós-colonial a ambientes culturais específicos? É possível afirmar que no Brasil há textos cujas características sejam definidas a partir das categorias do pós-colonial? Que postura o intelectual pós-colonial deve tomar frente ao terreno das diferenças culturais e ideológicas? A hibridação enquanto fenômeno empírico funciona como categoria epistêmica e política, visando à emancipação dos sujeitos históricos subalternizados?

Para se pensar sobre tais questionamentos, recorre-se a um importante ensaio do jamaicano Stuart Hall, intitulado Quando foi o pós-colonial? Pensando no limite, presente no livro Da diáspora: identidades e mediações culturais (2003). Ao focalizar o lugar do pós-colonial no universo histórico, epistêmico e político hoje, Hall rebate argumentos e críticas de teóricos como Ella Shohat, Anne McClintock e Arif Dirlik, demarcando características e objetivos da crítica pós-colonial.

3 Em Orientalismo (1996), Said aponta quatro elementos que redefinem o projeto de "orientalizar o oriente" a partir das "geografias ocidentais imaginativas e suas representações", preparando o "caminho do moderno orientalismo". Toma como análise inicial a narrativa Bouvard et Pécuchet, de Flaubert, para discutir o novo traçado das fronteiras imposto pelo colonialismo europeu que estende o espaço de ocupação e conhecimento. Os quatro elementos destacados são: o expansionismo; a confrontação histórica; a identificação solidária e a classificação. Este último significou o impulso de "classificar a natureza e o homem em tipos." (p.128) De acordo com Said, nos escritos de filósofos, historiadores, enciclopedistas e ensaístas, encontra-se "o caráter como designação na qualidade de classificação fisiológico-moral", assim, "o americano é vermelho, colérico, ereto, o asiático é amarelo, melancólico, rígido, o africano é negro, fleumático, frouxo” (p. 129). A influência das literaturas de viagens, das utopias imaginativas, das jornadas morais e das reportagens científicas fundamentou o expansionismo. O segundo elemento - o confronto histórico - permite que a Europa construa de si mesma uma imagem a partir da tradução do outro oriental realizado pelo intelectual europeu. Segundo Said, essa técnica aplicada pelo historiador comparatista ajudava "um europeu a conhecer-se melhor a si mesmo" (p.127). A identificação por solidariedade surge a partir da ideia de que todas as culturas são estruturadas organicamente, internamente coerentes, unidas por um espírito. Tal concepção, surgida no século XVIII, com Vico, Herder e Hamann, propicia o sentido do nacional, criando, assim, as diferenças de identidade que fomentavam a imaginação do ocidente em torno de um Oriente como uma "localidade exótica". Dessa forma, tais elementos serviram para a focalização mais nítida e extensa do Oriente, podendo, desta forma, ser dominado a partir de um estudo orientado pelo império. (SAID, Edward. Orientalismo. São Paulo: Companhia das Letras, 1996.) 
É a partir da temporalidade histórica e da geografia que Stuart Hall principia o debate acerca dos fundamentos que ordenam o pós-colonial. Na introdução de seu ensaio, aponta três questões chaves: quando foi o pós-colonial? O que se deve incluir e excluir de seus limites? E qual a fronteira que divide o pós-colonial de seus outros termos afins: o colonialismo, o Terceiro Mundo e o imperialismo?

O primeiro aspecto é pensá-lo à luz do colonialismo cuja característica histórica se define pela posição social dos envolvidos: colonizadores e colonizados. A pergunta é: como tal crítica reage hoje ao binarismo do momento histórico anterior? Nas palavras de Hall: "Que tipo de diferença é essa e quais as suas implicações para a política e para a formação dos sujeitos na modernidade tardia?" (HALL, 2003, p. 101).

Para responder a tais perguntas, Hall traz, em primeiro lugar, a avaliação de Ella Shohat que aponta "para a ambiguidade teórica e política da teoria; sua multiplicidade vertiginosa de posições, seus deslocamentos universalizantes e anistóricos e suas implicações despolitizantes" (HALL, 2003, p. 102). ${ }^{4}$ Tal posição coaduna-se com a de Anne McClintock. Para ambas, o conceito é "utilizado para marcar o fechamento final de um período histórico, como se o colonialismo e seus efeitos estivessem definitivamente fechados" (HALL, 2003, p. 102).

Outro crítico é Arif Dirlik que afirma que o pós-colonial é um discurso pós-estruturalista e pós-fundacional usado por intelectuais deslocados do Terceiro Mundo, que "estão se dando bem em universidades prestigiosas americanas" (HALL, 2003, p. 102). Dirlik aponta que o pós-colonial "menospreza a estrutura capitalista do mundo moderno" (HALL, 2003, p. 103).

Em relação aos apontamentos que acusam certa despolitização histórica da teoria pós-colonial, Hall argumenta que há, por parte dos autores, certa nostalgia em retornar a uma política bem definida de oposições binárias, em que se possam traçar e separar linhas claras entre os "bonzinhos dos malvados". Tais linhas "podem ter sido simples de traçar no passado, mas não são assim hoje em dia" (HALL, 2003, p. 104). De outro modo, isso não significa que não existam o "certo" e o "errado", que não haja opções políticas difíceis de tomar. Desta forma,

As posições políticas não são fixas, não se repetem de uma situação histórica a outra, nem de um teatro de antagonismos a outro. Afinal, não estamos todos, de formas distintas e através de espaços conceituais diferentes, buscando desesperadamente compreender o que significa fazer uma escolha política ética e se posicionar em um campo político necessariamente aberto e contingente? (HALL, 2003, p. 104-105)

4 Ella Shohat afirma e questiona que: The term 'post-colonial' carries with in the implication that colonialism is now a matter of the past, undermining colonia-lism's economic, political, and cultural deformativetraces in the present. As a signifier of a new historical epoch, the term 'pos-colonial', when compared with neo-colonialism, comes equipped with little evocation of contemporary power relations. What, then, is the meaning of post-coloniality when certain structural conflicts persist? How then does one negotiate sameness and difference within the framework of a 'pos-colonial' whose 'post' emphasizes rupture and deemphasizes sameness? (MATA, 2007, p.31) (O termo 'pós-colonial' carrega consigo a implicação de que o colonialismo tornou-se um problema do passado, desconsiderando os traços econômicos, políticos e culturais deformantes persistentes no presente. Como significante de uma nova época histórica, o termo pós-colonial quando comparado com 'neo-colonialismo faz pouca referência às relações contemporâneas de poder. Qual, então, é o sentido da pós-colonialidade quando certos conflitos estruturais persistem? Como então se negociam semelhanças e diferenças no interior da estrutura de um 'pós-colonial' cujo 'pós' enfatiza ruptura e desenfatiza semelhança?) (tradução do autor) 
Numa atitude similar, Homi Bhabha (1998) busca no termo negociação a chave para interpretar as questões do nosso tempo, balizado, entre outros aspectos, pela crise dos referenciais socialistas. Evita, naturalmente, a ideia conservadora de reformismo liberal. Porém interpreta a noção de negociação como "um evento de instâncias contraditórias e antagônicas que abrem lugares e objetivos híbridos de luta e destroem as polaridades negativas entre o saber e seus objetos entre a teoria e a razão prático-política" (BHABHA, 1998, p. 51).

O propósito de Bhabha é contestar o termo negação - componente crítico da modernidade - pois é uma categoria incapaz reconhecer hoje as identidades culturais e as concepções acerca de uma teoria da história:

Quando falo de negociação em lugar de negação, quero transmitir uma temporalidade que torna possível conceber a articulação de elementos antagônicos ou contraditórios: uma dialética sem a emergência de uma História teleológica ou transcendente. (BHABHA, 1998, p. 51)

Em condições históricas totalmente adversas, parece evidente que o momento de negação promovido pelos movimentos de resistência contra os valores dominantes seja a norma. Essa é a preocupação de Shohat quando acusa a dispersão e ambivalência discursiva do discurso pós-colonial, confundindo os agentes históricos da mudança social, dissolvendo-os em sujeitos atomizados da sociedade de classe.

Portanto, é preciso contextualizar as ações, impedindo que haja um fechamento prévio das estratégias em torno da identidade. No atual estágio da produção política e cultural o que fortalece mais os caminhos para emancipação social? Para alguns, os hibridismos étnico-culturais, assinalados pelo comunitarismo solidário, não revelam adequadamente as posições dos sujeitos na sociedade, mascarando situações de desigualdade e opressão.

Tomando como referência tal risco, o sociólogo português Boaventura de Sousa Santos adverte para certa euforia do discurso pós-colonial que, ao celebrar a condição híbrida diaspórica, esquece que a mesma tem sido utilizada "para ocultar as realidades imediatas, econômicas, sociais, políticas e culturais dos imigrantes ou das comunidades diaspóricas" (SANTOS, 2006, p. 240). Para o autor, o enaltecimento da diáspora e a promoção da estética da hibridez podem ocultar os "conflitos sociais reais em que os grupos imigrantes envolvidos, e sempre em posições de poder que lhe são desfavoráveis, como é o caso tangente da diáspora muçulmana no Ocidente" (SANTOS, 2006, p. 240).

Igualmente contestando os processos de hibridação, Fredric Jameson vê a importância das classes sociais como estratégia para renovação em vista de seu posicionamento estrutural. Partindo das representações althusserianas e psicanalíticas, Jameson enfatiza que

As categorias de classe são mais materiais, mais impuras e escandalosamente misturadas no modo pelo qual seus fatores determinantes ou definidores envolvem a produção de objetos e as relações por ela determinadas, assim como a força dos respectivos aparatos: podemos, desse modo, ver, através das categorias de classe, a base de pedra que sustenta o processo. (JAMESON, 1996, p. 347) ${ }^{5}$

5 Consciente do paradoxo, Jameson, de outro modo, escreve que "as classes são demasiado abrangentes para figurar como utopias, como opções que escolhemos e com que nos identificamos de forma fantasmática. A única gratificação oferecida pela categoria de classe é sua futura abolição" (JAMESON, 1996, p. 347). 
Em resposta a Jameson, Bhabha elege a comunidade como categoria crítica à hegemonia do capital monopolista globalizado. Tal figura perturbaria a grande narrativa do capital global, deslocando a ênfase dada à produção na coletividade de classe e rompendo a homogeneidade da comunidade imaginada da nação. Para o autor

A comunidade é o suplemento antagônico da modernidade: no espaço metropolitano ela é o território da minoria, colocando em perigo as exigências da civilidade; no mundo transnacional ela se torna o problema de fronteira dos diaspóricos, dos migrantes, dos refugiados. (BHABHA, 1998, p. 317)

As considerações do sociólogo Sergio Costa (2006) são importantes para se pensar as afirmações de Bhabha a respeito das estratégias de transformação social defendidas pelo pós-colonial. Costa sustenta que um dos aspectos que põe em questão a teoria pós-colonial como agenciamento da transformação e emancipação social articulada por Homi Bhabha é que este "evita a remissão à ideia de um sujeito que seja definido pelo vínculo a um lugar na estrutura social" (COSTA, 2006, p. 93). Para Bhabha, de acordo com Costa, "o sujeito é sempre um sujeito provisório, circunstancial e cingido entre um sujeito falante e um sujeito falado, reflexivo" (COSTA, 2006, p. 93). Para teoria pós-colonial de Bhabha, "a subversão possível é aquela relacionada com o deslizamento do sentido dos signos" (COSTA, 2006, p. 93-94). A ideia é de que os signos possuem possibilidades inesgotáveis de significação, podendo ganhar um sentido particular, ainda assim provisório e incompleto, num contexto determinado. "A eficácia da intervenção é também sempre contingente, aberta, indefinida: trata-se de uma ação dentro da área de influência do sujeito, mas fora de seu controle" (COSTA, 2006, p. 93-94).

Voltando às respostas de Hall acerca do lugar e dos limites da crítica pós-colonial, o autor concorda com Shohat sobre os riscos de uma universalização espúria do pós-colonial. Para tanto, é necessário estar atento para as suas discriminações e especificidades, observando uma distinção criteriosa das formações sociais e raciais. Isso significa que "nem todas as sociedades são pós-coloniais num mesmo sentido" (HALL, 2003, p. 107).

De outro modo, é preciso salientar que uma das principais contribuições do termo pós-colonial é ter dirigido a atenção para o fato de que a colonização nunca foi algo externo às sociedades imperiais. Sempre esteve inscrita nelas, da mesma maneira como se tornou "indelevelmente inscrita nas culturas dos colonizados" (HALL, 2003, p. 108). Assim, "as diferenças entre as culturas colonizadora e colonizada permanecem profundas. Mas nunca operaram de forma binária, nem certamente o fazem mais" (HALL, 2003, p. 108).

É preciso reafirmar essa dupla inscrição do discurso pós-colonial. Com efeito, este não se restringe à descrição de uma determinada época ou sociedade. Relê a colonização como parte de "um processo global essencialmente transnacional e transcultural". O póscolonial produz uma "reescrita descentrada, diaspórica e global", através das "grandes narrativas imperiais do passado, centradas na nação" (HALL, 2003, p. 109).

Recusa igualmente uma cronologia do pós-colonial. É preciso olhá-lo para além das periodizações históricas, ainda que o rompimento com o colonialismo tenha sido um fato decisivo na formação dos novos Estados-Nação. De outro modo, o cenário atual não liquida inteiramente a inscrição colonial, sobrevivendo seus efeitos nas periferias das metrópoles.

Ainda que haja a sobrevivência de resquícios do colonialismo, não se pode mais mapear sua política, nem considerá-la idêntica àquela que vigorou no passado. Frente a este universo, simultaneamente de ruptura e continuidade, é que o pós-colonial faz proliferar 
histórias e temporalidades, entrelaçando-as e introduzindo figuras da diferença cultural nas narrativas eurocêntricas.

O pós-colonial faz multiplicar as conexões, em especial as descentradas e laterais, registrando os movimentos migratórios que compõem o mundo. Exalta as questões do hibridismo, da "indecidibilidade cultural" e as complexidades da identificação diaspórica que interrompem a volta a "histórias originais fechadas e centradas em termos étnicos" (HALL, 2003, p. 114). ${ }^{6}$

Seguindo os argumentos de Hall, o pós-colonial significa o processo inteiro de expansão, exploração, colonização e hegemonia imperial que produz a fisionomia da modernidade capitalista europeia. As narrações pós-coloniais deslocam as estórias da modernidade capitalista de seu centro europeu para as periferias dispersas do mundo, provocando uma "interrupção crítica na grande narrativa historiográfica" (HALL, 2003, p. 113). Esse longo processo transforma as próprias colônias ou mesmo enormes extensões do globo em regiões diaspóricas, pondo em questão ao que se poderia imaginar como culturas de origem.

Os movimentos transversais, transnacionais e transculturais, marcados desde sempre na história da colonização, têm ocorrido de distintas formas para alterar as relações de dominação e resistência inscritas em outras narrativas e formas de vida. Para Hall,

O outro deixou de ser um termo fixo no espaço e no tempo externo ao sistema de identificação e se tornou uma exterioridade constitutiva simbolicamente marcada, uma posição marcada de forma diferencial dentro da cadeia discursiva. (HALL, 2003, p. 116)

Nesta breve exposição, estão explícitos os conceitos que norteiam a crítica pós-colonial que, por sua vez, faz avançar um novo e frutífero processo metodológico e teórico aos estudos de literatura. Levando em consideração a ideia de uma literatura transnacional, marcada pela hibridação e mestiçagem, por questões de diferença cultural e histórica, trazidos pela crítica pós-colonial, recorre-se ao romance Estação das chuvas (1996), de José Eduardo Agualusa, como forma de ilustrar analiticamente tais sentidos teóricos, enfatizando as noções de hibridismo étnico-cultural no presente texto do autor.

Em Estação das chuvas, José Eduardo Agualusa dá continuidade a alguns temas e teses que marcam sua obra. As mais evidentes são a rememoração crítica dos processos históricos de seu país - as chamadas guerras de libertação e civil - e seus efeitos traumáticos. Igualmente o apagamento entre o ficcional e o histórico, com ênfase nas relações biográficas e autobiográficas e o enfoque positivo à mestiçagem cultural, assinalada pelos deslocamentos geográficos se encontram presentes em seus romances. A problematização étnico-racial e a apreciação das identidades nacionais, bem como o diálogo das culturas afro-ibérico-americanas e asiáticas também fazem parte das preocupações do autor. São destaques ainda às tradições orais e religiosas, os intertextos vinculados ao cânone de língua portuguesa na África e o tratamento dado à figura feminina.

6 Paul Gilroy nos lembra que o conceito de diáspora pode oferecer alternativas reais para "a inflexível disciplina do parentesco primordial e a fraternidade pré-política e automática". Como alternativa à metafísica da raça, da nação e de uma cultura territorial fechada, a diáspora embaraça a dinâmica histórica e cultural do pertencer ao revelar "parentescos sub e supranacionais, e permitindo uma relação mais ambivalente com as nações e com o nacionalismo.” (GILROY, 2008, p.18-19) 
Particularmente, em Estação das chuvas, predominam episódios da vida política de Angola, em especial as guerras de libertação e civil e a sobreposição de fatos históricos e ficcionais, embaralhando figuras reais e inventadas. Estes são os assuntos que boa parte dos estudos $^{7}$ acerca do romance fazem referência, ou seja, a análise dos conflitos que marcaram a história de Angola no decorrer do século XX, em especial, o combate contra o colonialismo português e luta pela independência do país através dos movimentos de libertação nacional. $\mathrm{O}$ período do pós-independência igualmente merece atenção em tais trabalhos de investigação, enfatizando as divergências dos movimentos de libertação que conduzem dirigentes à prisão e ao exílio. Menciona igualmente a tentativa de golpe de estado ocorrida em 27 de maio de 1977, fato este que leva o regime de Agostinho Neto, através do MPLA, a recrudescer contra aqueles que se opunham às práticas políticas do partido.

Como atesta os principais episódios do livro, a nação afunda num estado de extrema violência. Os próprios membros do governo são investigados, interrogados e presos. A UNITA e a FNLN tornam-se clandestinos, iniciando uma ofensiva ao poder do MPLA logo após a independência, dando início a uma guerra intestina de longa duração. Estação das chuvas, assim, procura estabelecer uma estreita relação com a história. Para tanto, o texto se organiza em torno da narração de um jovem jornalista, interessado, entre outros aspectos, na pesquisa da obra e biografia de Lídia do Carmo Ferreira, poetisa que exercera a atividade política ao lado dos principais nacionalistas.

O narrador, igualmente envolvido no processo de independência, sofrendo as sanções do período ao militar num pequeno partido de esquerda, redige pequenos capítulos sobre a história de vida da poetisa, exposta a partir de entrevistas feitas com a escritora e de testemunhos de amigos próximos. O mesmo procura divulgar os poemas da escritora. Simultaneamente, menciona outras personagens que, além das ações revolucionárias, estiveram próximas à Lídia, revelando os contatos que a mesma mantinha com um grupo de intelectuais que desejavam criar um movimento cuja finalidade era "descobrir Angola" frente às políticas colonialistas de Portugal.

Ainda que Estação das chuvas não priorize o tema da mestiçagem, assunto em destaque em outras obras de Agualusa, levar-se-á em conta tal dimensão, tomando como referência um capítulo em que a narrativa menciona uma discussão entre Mário Pinto de Andrade, importante intelectual angolano, ligado ao movimento da negritude, e a poetisa Lídia do Carmo Ferreira. O debate se deve em torno da organização e do título do livro Poesia negra de expressão portuguesa, organizado por Mário e José Francisco Tenreiro. ${ }^{8}$

7 Enumeramos alguns trabalhos a seguir: Contradição, história e política em Estação das chuvas, de José Eduardo Agualusa, ensaio de Fabiana Francisco Tibério; As personagens começam a existir no momento em que nos aparecem em sonhos - construção e representação de personagens agualusianos, ensaio de Mariana Carvalho; Lídia pelos caminhos de Angola: as intersecções entre literatura e história no romance Estação das chuvas, de José Eduardo Agualusa, dissertação de Franciele Rodrigues Guarienti; Literatura e História: as mulheres de Agualusa nos romances Nação crioula e Estação das chuvas, ensaio de Edvaldo Bergamo; As marcas da violência: uma leitura de Estação das chuvas e Maio, mês de Maria, dissertação de mestrado de Osvaldo Sebastião da Silva.

8 Em prefácio à edição de 1982 do caderno Poesia negra de expressão portuguesa, Manuel Ferreira escreve: "Em 1953 dois jovens africanos, Francisco Tenreiro (são-tomense) e Mário de Andrade (angolano) lançavam em Lisboa um caderno tablóide de 18 páginas, intitulado Poesia negra de expressão portuguesa" (1982, p. 13). O caderno abre com uma introdução de Tenreiro, fechando com uma nota final de Mário de Andrade. Como se verifica na leitura do caderno, os poemas ao todo são nove: um em espanhol do cubano Nicolás Guillén e os restantes em língua portuguesa. Os poetas presentes na antologia representam três das cinco ex-colônias e são os seguintes: Alda Espírito Santo e Francisco Tenreiro (Santo Tomé e Príncipe); 
No capítulo, Lídia, com a morte do avô, decide deixar Lisboa, cidade fria, sentindo falta do vigor da natureza de Luanda. Nesta, como observa Lídia, "o sol arde. Os pássaros cantam de euforia" (AGUALUSA, 2000, p. 79). Como diz a personagem, "dezembro é um mês de risos e calor - o bom calor do chão" (AGUALUSA, 2000, p. 79). Ali, homens sentam-se à sombra a beber cerveja, conversando longamente. "As comadres perdoam-se ofensas antigas. Há um esplendor de acácias rubras pelas ruas" (AGUALUSA, 2000, p. 79). Todavia, não retorna para Luanda. Viaja para Berlim. Com a notícia recebida da morte de Jacinto do Carmo Ferreira, o avô, sente-se confusa e abalada. Vende todos os objetos possíveis e parte para Alemanha sem se despedir de ninguém. Ao mesmo tempo, para complicar ainda mais, Mário Pinto de Andrade zangara-se com ela. Como explicara Lídia ao narrador jornalista, numa das entrevistas realizadas, tal desavença começara "com uma grande discussão sobre a negritude" (AGUALUSA, 2000, p. 80). Segundo a poetisa, Mário Pinto de Andrade pretendia incluir alguns poemas seus "numa coletânea de poesia negra de expressão portuguesa" (AGUALUSA, 2000, p. 80). Lídia ressalta que, naquela altura, Mário já se correspondia com Cesaire, Senghor, Diop e Depestre, tendo escrito dezenas de artigos e palestras sobre temas como A expressão do Kimbundu, A literatura negra e seus problemas, O problema linguístico-africano, ajudando a fundar, com Francisco José Tenreiro, Agostinho Neto e Alda Espírito Santo, entre outros, um Centro de Estudos Africanos.

De acordo com Lídia, com a publicação do Caderno de poesia negra de expressão portuguesa, Mário pretende que a antologia se torne a primeira manifestação coletiva da negritude em língua portuguesa. Na visão do intelectual, tal edição demonstraria com clareza de que os poetas negros de língua portuguesa começariam "a trilhar um caminho próprio", exercitando também os "seus timbres para cantar na grande sinfonia humana" (AGUALUSA, 2000, p. 80).

Em depoimento ao narrador, Lídia argumenta que não percebe "que fosse negra a sua poesia", problematizando a aproximação entre gênero literário e a condição racial. Segundo a poetisa,

- É um equívoco - tentou explicar a Mário de Andrade. Aquilo que eu escrevo não tem especialmente a ver com o mundo negro. Tem a ver com o meu mundo, que é tanto negro como branco. E sobretudo é o meu mundo! Se quiseres incluir trabalhos meus muda o nome da antologia para "Caderno de poetas negros", mas ainda assim será um disparate, como fazer um "Caderno de Poetas Altos" ou uma Coletânea de Poesia das Mulheres Obesas"... (AGUALUSA, 2000, p. 80-81)

Mário de Andrade acusa Lídia de "falta de solidariedade com os seus companheiros", acrescentando que na fase de luta em que ambos estão comprometidos, a ausência de solidariedade "confunde-se com traição" (AGUALUSA, 2000, p. 81). Em resposta, Lídia diz não se identificar com a negritude, ainda que compreenda sua importância. Afirma que o universo de ambos é outro.

Tu, como eu ou o Viriato da Cruz, todos nós pertencemos a uma outra África; àquela mesma África que habita também nas Antilhas, no Brasil, em Cabo Verde ou em São Tomé, uma

Agostinho Neto, António Jacinto e Viriato da Cruz (Angola) e Noémia de Sousa (Moçambique). No referido prefácio acima indicado, Manuel Ferreira expõe as justificativas para inclusão de Guillén e a ausência de poetas cabo-verdianos segundo os organizadores do volume. (FERREIRA, 1982) 
mistura da África profunda e da velha Europa colonial. Pretender o contrário é uma fraude. (AGUALUSA, 2000, p. 81)

Indignado e vitorioso, Mário mira Lídia, exaltado: "isso é Gilberto Freyre! Isso é a maldita mistificação luso-tropicalista"9 (AGUALUSA, 2000, p. 81). Mário sai ofendido e Lídia crê que perdera o amigo para sempre. Inquieta, Lídia não consegue esquecer o assunto, convencida de que está correta. De acordo com a poetisa, "o próprio Senghor sofre da nostalgia do universo crioulo onde ainda decorreu a sua infância" (AGUALUSA, 2000, p. 81). Para ela, se para o próprio poeta senegalês era assim, como não pensar nos poetas e poetisas que Mário quer incluir na antologia? Lídia observa as condições de mestiçagem nos poetas que Mário pretende adicionar na coletânea:

Alda do Espírito Santo, negra de São Tomé, cantora das paisagens crioulas da sua ilha. Francisco José Tenreiro, também santomista, mestiço e crioulo, a vida quase toda vivida em Portugal. Noémia de Sousa, uma jovem moçambicana, trazendo à flor da pele a inquietação dos muitos sangues misturados: o pai, natural da Ilha de Moçambique, com a inevitável ascendência indiana, árabe, banto e portuguesa, e a mãe uma senhora mulata, filha de uma negra e de um alemão. (AGUALUSA, 2000, p. 81-82)

Na sequência do capítulo, para fortalecer suas ideias, Lídia enumera alguns poemas que expressam a importância do hibridismo cultural e racial. Chama a atenção da inclusão dos poetas Viriato da Cruz e Agostinho Neto na antologia, observando aspectos bíblicos nos poemas de Neto que a deixava desconcertada. Para ela, o caso mais curioso e singular pertence à figura do poeta António Jacinto. Luandense, filho de portugueses, quase ficara de fora da coletânea, pois era branco. E os angolanos brancos, para Mário e Lídia, eram motivos de desconfiança em virtude da profundidade de seu enraizamento na cultura local e negra.

Ambos sabiam que os brancos gostavam de participar nas iniciativas culturais, mas só até certo ponto, e raramente estavam dispostos a prescindir dos seus privilégios de raça e classe. Por exemplo, nas farras de estudantes africanos os jovens brancos apareciam apenas durante as primeiras horas. A seguir iam continuar a noite nas brilhantes festas dos seus colegas metropolitanos, onde não se viam negros nem mestiços. (AGUALUSA, 2000, p. 83)

A argumentação de Mário a favor da inclusão de António Jacinto era de que ninguém poderia acusá-lo de racismo, acrescentando, ainda, que pouca gente fora de Angola sabe que o poeta é branco. Ademais, o amigo de Lídia deseja incluir na antologia o poeta cubano Nicolás Guillén que, segundo Mário, era a "voz mais ampla da negritude nas

9 Em certa altura, a assimilação racial servira de prerrogativa universalmente aceita, vista como efeito exemplar de um colonialismo cordial. O luso-tropicalismo, desenvolvido por Gilberto Freyre, alimentou a doutrina colonial portuguesa a partir da década de 1950 quando havia ventos favoráveis a partir de 1945 às libertações dos povos colonizados. De acordo com a professora Maria da Conceição Neto, as teorias da mestiçagem do estudioso pernambucano foram amplamente utilizadas pelo governo português como suporte ideológico da defesa das colônias na África. Procurando desmistificar tal doutrina, Neto reage aos ideólogos do governo de Salazar que afirmavam: "Portugal, apesar dos erros de alguns dos seus maus filhos, veio à África para formar uma comunidade luso-tropical, onde negros e brancos vivessem mais felizes. A ideia da multirracialidade estava já no seu corpo que era um mosaico de raças.” (NETO, Maria da Conceição. Ideologia, contradições e mistificações da colonização de Angola no século XX. Revista Lusotopie, 1997, pp. 327-359) 
Américas" (AGUALUSA, 2000, p. 84). Contrapondo-se a Mário, na opinião da poetisa, a inclusão de Guillén define o caderno na sua essência, não se tratando, neste caso, de negritude. Para Lídia, a "genialidade de Guillén foi conseguir trazer para sua poesia culta a alma crioula de Cuba” (AGUALUSA, 2000, p. 84). Nicolás Guillén, no dizer da poetisa, não recupera as tradições iorubas, em contrapartida, reproduz "os modelos de miscigenação que durante séculos se produziram na ilha", fundindo a "tradição africana com a tradição europeia" (AGUALUSA, 2000, p. 84).

Após a citação de um fragmento poético de Guillén em que o caráter híbrido das relações étnico-culturais é exposto, o capítulo encerra-se com Lídia pensando melancolicamente sobre tal discussão, recordando, ao mesmo tempo, os risos de ambos que apagariam o rancor de tal debate. Os resultados de tais empreendimentos e configurações trazem a importância dos processos de hibridação como condição originária dos diversos agrupamentos sociais, em que pese os graus e modos de participação e integração comunitárias. ${ }^{10}$

Francisco José Tenreiro (1982), igualmente organizador e colaborador de Caderno de poesia negra de expressão portuguesa, fornece uma bela reflexão acerca do tema da mestiçagem ao escrever o poema intitulado Canção do mestiço. Nele, o poeta diz

\section{Mestiço \\ Nasci do negro e do branco/ e quem olhar para mim/ é como se olhasse/ para um tabuleiro de xadrez:/ a vista passando depressa/ fica baralhando cor/ no olho alumbrado de quem me vê. Mestiço! \\ E tenho no peito uma alma grande/ uma alma feita de adição. (TENREIRO, 1982, p. 61)}

O fragmento explicita, entre outros aspectos, uma preocupação crítica com a condição binária da identidade, estabelecida a partir da fixação e segregação do eu e do outro. Há, seguindo as reflexões de Stuart Hall, a partir da categoria da diferença proposta por Derrida, uma recusa ao binarismo identitário como fundamento das relações raciais e culturais. Nessa direção, "não se trata da forma binária de diferença entre o que é absolutamente o mesmo e o que é absolutamente Outro" (HALL, 2003, p. 60). De acordo com Hall, apoiando-se ainda em Derrida, trata-se de "uma onda de similaridades e diferenças, que recusa a divisão em oposições binárias fixas" (HALL, 2003, p. 60). A representação de movimento através da imagem da onda é verificável no poema de Tenreiro quando o sujeito poético passa a vista rapidamente, dirigindo-se em direções variadas sem ancorar, previamente, num ponto fixo. "O significado aqui não possui origem nem destino final, não pode ser fixado, está sempre em processo e 'posicionado' ao longo de um espectro" (HALL, 2003, p. 61). Para o estudioso, "o seu valor político não pode ser essencializado, apenas determinado em termos relacionais” (HALL, 2003, p. 61).

$10 \mathrm{O}$ tema da mestiçagem é vasto e complexo. Em O pensamento mestiço (2001), Serge Gruzinski evidencia tal complexidade a partir de algumas questões, assim sintetizadas: As misturas resultantes da expansão colonial expressam uma reação à dominação europeia? As misturas são repercussões da dominação europeia e até mesma uma forma astuciosa de enraizar nossos costumes no seio das populações subjugadas? Até que ponto uma sociedade ocidental pode tolerar a eclosão proliferadora de expressões híbridas? Que sentido, que limites e que ciladas se escondem na metáfora tão cômoda da mistura?Como se desenvolve um pensamento mestiço? A obra de Gruzinski aborda as relações coloniais ibéricas no continente americano, com destaque para o México. 


\section{Considerações finais}

Ainda que o hibridismo étnico e cultural seja enfatizado por Hall, convém assinalar o momento dramático da experiência da luta anticolonial como função reparadora dos valores do negro. ${ }^{11}$ Numa perspectiva histórica, o uso da raça como posição libertadora das nações colonizadas, em especial na África, serviu como paradigma de resistência ao olhar branco europeu. Como assinala Homi Bhabha (1998,) o olhar da resistência é o "olhar anômalo da alteridade" (BHABHA, 1998, p. 134). Dessa forma, os movimentos da negritude iniciados na década de 1930 contribuíram decisivamente na visibilidade do "problema" do negro em diferentes espaços nacionais. Na esteira dessa movimentação intelectual, as literaturas africanas aliaram-se amplamente, inserindo-se aí aquelas voltadas ao universo de língua portuguesa.

No período colonial tal tema se tornou uma das balizas das literaturas africanas de língua portuguesa. Igualmente após o período de libertação nacional, somando-se à história recente, o tema continuou a vigorar. Os olhares, porém, são outros, impregnando-se de crítica e ironia. De outro modo, a permanência do conflito racial como assunto traduz de maneira clara o longo fardo de subjugação colonial imposta pela minoria branca, alicerçada na escravidão e na consolidação das ações imperialistas através de princípios jurídicos e culturais.

A duradoura permanência do homem branco europeu em espaço africano trouxe, desta forma, a questão da mestiçagem. Ainda que a situação fosse explorada politicamente pelos governos, atendendo a ideologia colonial, em especial a portuguesa, os resultados posteriores parecem conferir uma valorização das trocas culturais e raciais como pressuposto inerente a uma realidade multicultural. É em defesa da mestiçagem como categoria exemplar que Lídia provoca seu amigo Mário Pinto de Andrade, a exemplo de outra personagem criada por Agualusa, o escritor Bartolomeu Falcato que se manifesta, com convicção, acerca de tal tema:

Eu acho que a mestiçagem é por natureza revolucionária. A mestiçagem biológica, cultural, pressupõe inevitavelmente uma ruptura com o sistema, a emergência de algo novo a partir de duas ou mais realidades distintas. (AGUALUSA, 2009, p. 227)

Preocupado com a essencialização da figura do negro, expressão de uma ideologia baseada na pureza da identidade, produto de uma percepção binária do mundo, Hall propõe uma estética diaspórica, expressão cuja resultante configura-se no termo hibridismo, reafirmando, como já foi aqui exposto, a coexistência de mais de uma cultura, articulada sob o signo das confluências históricas e existenciais.

É sob tal categoria, entrevista conceitual, existencial e historicamente que a obra de Agualusa se projeta no conjunto da produção literária de língua portuguesa, dialogando sempre com a história de Angola, cruzando-a com outras regiões e culturas do planeta. Em Estação das chuvas, o escritor realiza tal debate, situando-o num único e significa-

11 Ao discutir questões de identidade e diferença, inspiradas no conflito servo-croata, Kathyryn Woodward observa que a "emergência dessas diferentes identidades é histórica; ela está localizada em um ponto específico no tempo." Neste caso, uma das formas pelas quais "as identidades estabelecem suas reivindicações é por meio do apelo a antecedentes históricos, sendo a redescoberta do passado parte do processo de construção da identidade" (WOODWARD, 2008, p.11). 
tivo capítulo, que serve de referência para se compreender a totalidade de sua produção romanesca, sugerindo uma resposta de um possível sujeito histórico questionador das realidades nacionais homogêneas e excludentes.

Referências

AGUALUSA, José Eduardo. Barroco tropical. Lisboa: Dom Quixote, 2009. . Estação das chuvas. Rio de Janeiro: Gryphus, 2000.

ANDRADE, Mário P. e TENREIRO, Francisco. Poesia negra de expressão portuguesa. Prefácio de Manuel Ferreira. Linda-a-Velha: Editor África, 1982. BHABHA, Homi. O local da cultura. Belo Horizonte: Ufmg, 1998. COUTINHO, Eduardo F. Literatura comparada na América Latina. Rio de Janeiro: Eduerj, 2003.

COSTA, Sérgio. Dois Atlânticos: teoria social, anti-racismo, cosmopolitismo. Belo Horizonte: Ufmg, 2006.

GILROY, Paul. O atlântico negro. Rio de Janeiro: Editora 34, 2008.

GRUZINSKI, Serge. O pensamento mestiço. São Paulo: Companhia das Letras, 2001. HALL, Stuart. Da diáspora: identidades e mediações culturais. Belo Horizonte: Ufmg, 2003.

JAMESON, Fredric. Pós-Modernismo: a lógica cultural do capitalismo tardio. São Paulo: Ática, 1997.

SAID, Edward. Cultura e imperialismo. São Paulo: Companhia das Letras, 1999. .Orientalismo. São Paulo: Companhia das Letras, 1996

SANTOS, Boaventura de Sousa. A gramática do tempo. São Paulo: Cortez, 2006. TENREIRO, Francisco José. Coração em África. Linda-a-Velha: Editor África, 1982. WOODWARD, Kathryn. Identidade e diferença: uma introdução teórica e conceitual. In: SILVA, Tomaz Tadeu (org. e trad.). Identidade e diferença: a perspectiva dos estudos culturais. Petrópolis: Vozes, 2000.

Recebido em: 09/04/2019; Aceito em: 23/04/2019 